\title{
Special issue on China: \\ Re-thinking China's economic transition and development in the post-crisis era
}

\section{Introduction: China facing new challenges, beyond the global crisis}

\author{
Roberta Benini · He Liping
}

Published online: 16 February 2013

(C) Springer Science+Business Media New York 2013

China facing the global crisis The present international financial and economic turmoil in Western economies have accelerated significant structural changes of the Chinese economy but critical factors were already at work: the international crisis has speed up these processes and eventually amplify their impact.

China' answer to the global crisis, with growing State spending has been appropriate, decisive and able to temporarily sustain growth. But such policies cannot be kept for long if other structural internal factors-such as reforms-are not going to change and consolidate quality growth factors. So there is a problem of sustainability in the near future (Lardy 2012).

However the rapid increase of state investments in hard infrastructures (transport means) investments in rural construction, green economy, social services, (Fardoust et al. 2012), as part of the large stimulus package—have signified a contribution to the amelioration of the economic environment, improvement of territorial mobility, contributing to alleviate at some extend income inequalities. The questions are then related to future steps for policy agenda for next decades to come (World Bank 2012).

Which are the main challenges head for China in the next decades There is a general consensus among scholars and analysts, that the growth patterns on which China has build its extraordinary successful development have lost momentum since, internally and internationally, the conditions have fundamentally changed. Shrinking of world demand for import, together with the increase of cost factors, both internally such as labour costs, and internationally such as commodities' prices, in particular energy prices. The costs of the intensive development has

\footnotetext{
R. Benini (西)

University of Bologna, Bologna, Italy

e-mail: roberta.benini2@unibo.it
}

\section{H. Liping}

School of Economics and Business, Beijing Normal University, Beijing, China

e-mail: liping@cei.gov.cn 
brought also unsustainable pollution and environmental disasters, that are becoming obstacles to further growth, in particular in the large metropolitan areas. The decreasing export demand from Western countries, together with the increasing competition for investment location and trade from other emerging countriesincluding East and South Asia neighboring countries-have contributed to reduce significantly the export dimension, as pillar of growth. The slowing down of FDI to China is also a correlated consequence of the present rapidly changing scenario.

In the last three decades, the export led growth model has allowed China to rapidly insert itself into the world production system-within the accelerated fragmentation of the value production chain (see F. Lemoine and K. C. Fung in this Issue)_but has brought to excessive unbalances of the economy, coupled with protectionist control of financial markets, repressed domestic consumption and excessive saving accumulation.

Gaps in income distribution have been ever enlarging, and the trend appears to be unstoppable, together with too slow consumption increase in domestic markethousehold revenue still not increasing at a significant pace. Whilst the poverty rate has declined in the course of the last decades (World Bank 2012; OECD 2010, and see paper R. Herd in this Issue), income and regional disparities are growing again, although their statistical record is always extremely difficult to measure and subject to different interpretations.

A progressive ageing population and a demographic decline are going to represent negative factors for the future labour reserves, eroding the base for an extensive development: this is putting in perspective additional stress on the already "infant" social policy and pension schemes. This unfavourable demographic trend, can also be a further incentive to an acceleration of technology and innovation-base development.

Hidden risks have been accumulated in China's financial and public systems, as returns to investment begin to show a tendency of scaling down (see Fan Gang, He Liping and alias paper in this Issue).

The large trade surplus have contributed to the creation of huge currency reserves (see F. Lemoine and Z. Zhang and alias papers in these Issue) that today is source of a certain anxiety at international level (Lardy 2012; Subramanian 2011). However the rising costs of labour and commodities are rapidly worsening the term of trade and the current trade surplus is also declining (IMF 2012, 2011). In perspective the current account surplus could further fall, as result of the progressive "expected" rebalancing of the economy.

From planned economy to market economy the peculiar path followed by China often perceived as "special case", has been a complex mix of a prudential approach based on empirical "step by step" method, using "trial and error" path in an evolutionary vision, coupled with a fundamentally stable and centralized control of the policy-makers institutions, both central and peripheral (Lin 2004, 2011). The stability of the institutions, along all these decades, since the starting of reforms in 1979, even if progressively changed, is indeed a fundamental pillar of the peculiarity of the Chinese way to economic development. 
China, on the opposite of the former Eastern European transition countries, has adopted not a Bing-Ban or Shock Therapy approach, by definition macro-economic, but a gradual approach based on micro-foundation (Lin 2004, 2011), that has allowed to create slowly the base for capital accumulation, workers' ability and knowledge, embryonic entrepreneurial capacities and capabilities, favoured by the adaptation to the inward investments flows (FDI). This dual track policy has been fundamental for building the new economic bases, sustaining China's high growth for more than three decades, on one hand, but keeping away from international competition, the large State owned companies (SOE), on the other hand, creating distortions in the domestic economy. This dual track policy has exhausted its historical role and became a break to further expansion. Too tight control over domestic economy like service sector and financial markets, but also the undefined borders between State ownership and private ownership, the latter slowly increasing without a declared de-jure "privatization", need to be taken into account for lifting these distortions.

Changing the quality of growth' factors At this turning phase for China' growth, many are the fields for improving and speeding up policy reforms, including further openness of domestic service sectors and financial markets, to lift obstacles to more conducive conditions for businesses to growth in particular small and medium companies; to speed up the reform concerning SOE; to consolidate the system of public finance, reducing its hidden risks and enhancing its capacity for public service and to rationalize social management in order to provide for people more equal access to employment, education, and social insurance.

To regulate the informal migration flows that have been implicitly a tool for accompanying and sustaining investment cycles-one of the corollary of the same export-led model, based on cheap and flexible manpower. Migration remains a "grey areas" with lack of access to social care and decent housing (see R. Herd paper in this Issue). The question of labour market regulation, together with the building of an efficient safety-net system, to pursue more advanced social policies for softening income disparities and limiting the informal (grey or black) labour market to grow acquires, in this phase, new momentous. To this regard the strengthening of an active social policy is an integral part of the reform process and progressive upgrading of China quality of growth.

The process of RMB internationalization has been moving forward significantly in the recent years, partly as a result of rising weight of Chinese trade and economy in the world market. Yet the convertibility of the currency is lagged behind considerably in many aspects (see H. Gao paper in this Issue). The old-stylized restriction on financial flows across borders has undermined the aim at pursuing the establishment and development of an international financial centre in the country. The realisation of the aim would also help to increase the efficiency of capital market in the economy, that in turn would undoubtedly support productivity improvement and sustainable growth in China's corporate sector.

The contributions of the authors The Special Issue is organized around six main themes that cover the most relevant macro-issues: (i) the analysis of China 
economic growth patterns and the constraints that is facing in the medium and long term perspective; (ii) the challenges of China' integration into the world economy, from insertion into the global production sharing to new stage, China becoming new player of world investments; (iii) trade specialization and production sharing components are further analysed comparing China' with the other large emerging economy, India, on the base of their respective comparative advantages; (iv) The possible future convertibility of the RMB and the policy implications for alternative scenarios; (v) The large size of currency reserves that China cumulated in the last decade, is the subject of the analysis and original interpretation; (vi) the analysis of the progress made in the field of social policies, covers one of most crucial policy issue for present and future China growth perspective.

Gang Fan, Liping He, Xiaoyun Wei and Liyan Han in their paper China's Growth Adjustment: Moderation and Structural Changes analyse the economic factors that have affected negatively —on the medium-long term perspective- the growth, that has led to a progressive declining of capital returns. Three main factors are identified: as excessive reliance on export, pillar of the long term past three decades period of high growth rate-as result of both, declining demand from Western countries in a situation of global turmoil, but also a mounting competition from other emerging countries, at a different stage of development vis-à-vis China; the excessive energy-use intensity that implies costs rising and pollution; and the growing labour costs favoured also by diminishing of demographic growth. Taking these factors into consideration the authors underline that China cannot be able to keep the same high pace of growth of the previous period, suggesting for the years ahead, a possible growth rate around $8 \%$ yearly, that means two points less than the previous average period. Moderation and cautious approach for the future policy would be the most appropriate choice, also pursuing reforms for re-balancing some main evident distortions, such those between consumption and investment; progressive moderate decline of exports relayed by progressive increasing of domestic consumption; reduction of the economic disparities - that have accelerated in recent years-between coastal regions and internal Western regions.

Françoise Lemoine in her paper From Foreign Trade to International Investment: A new step in China Integration with the world economy, underlines the changing conditions that have shaped the insertion of China into the world economy in the context of the global crisis. Declining world demand and mounting of protectionism have render the pursuing of the previous export led model progressively obsolete, together with internal changes, related mainly to cost factors and declining demography. The paper analyses the features that has allowed China to fully exploit the world fragmentation of production chain. China has rapidly specialized on processing trade — what explains the unusual — for its country' sizehigh rate of China's openness over GDP. But the main impressive feature of the structural changes affects the technology content of the products, shifting from traditional labour intensive sectors, like textile, to computer and electronics. Increasing diversification and up-grading of technology content of exports goodswhilst at present still dominated by multinationals from advanced countries that pursued assembly activities, comparing with fully Chinese origin companies- 
indicates new feature for China. Thus new challenges are ahead of China, for new quality growth's factors, and its growing influence on world economy as source of world investments.

K.C. Fung, Hsiang-Chih Hwang, Francis Ng, Jesus Seade, in their paper Production Networks in China and India: A Comparative Analysis, analyse through a detailed and original analysis, the comparative specializations of China and India and their respective insertion into the world economy. The regional dimension-for China is Greater China with Hong-Kong and Macao, and for India is South Asia (India, Pakistan and Sri Lanka) enlarge the screen of the analysis for the importance of the respective "Hubs". The deepening of the global production chain networkwith the intensification of de-location processes in the 1990ies, from advanced countries toward East and South Asia, off-shoring growing parts and components production and assembly-has created new specializations in the latter countries, improving their respective comparative advantages.

Some main evidence from the empirical analysis confirms the dominant role of China and East Asia in the production sharing system for manufacturing trade, whilst less is for the case of South Asia and India, more agricultural, mining and service oriented.

Thus China and India show different patterns related also to their diverse sector specialization and market oriented infrastructures, educational capacities and R\&D policies.

Haihong Gao in her paper Convertibility as a step for the RMB Internationalization analyses the challenges related to a possible future RMB convertibility, the pre-conditions and the alternative policy' options that China could take. The current financial crisis has increased the instability of the current international monetary system and China is looking for a diversified reserve currency system including also the Yuan. After reviewing the literature in the field of currency convertibility, underlines different approaches that could be adopted for accompanying the deepening of the RMB internationationalisation-for the time being. The scope and scale of international use of the RMB is still limited, and is mainly facilitated by official agreements. There are different views on the speed and path of domestic financial reform with regard to the internationalization of the RMB, especially on three aspects: capital account liberalization, domestic financial market development, and exchange rate regime. The author suggests that the government choice should be a "market-driven" rather than a planned policy objective. Therefore a step by step approach is suggested starting from trade settlement to the broader policy measures. Domestic financial reforms need to be pursued, like flexible exchange rate, market oriented interest rate and deepening financial market.

Zhichao Zhang, Frankie Chau, Li Xie in their paper Accumulation of Large Foreign Reserves in China: a behavioral perspective question about the massive accumulation of reserves that reaches an unprecedented size in China in the last decade, exceeding any "optimal reserve" in any other country. They review the literature on this issue and they underline the non satisfactory explanations that they suggest for such phenomena. Most of the studies have concentrated on the cost-benefits of holding reserves, whilst recently new approach has been proposed looking at "welfare" implications based on "utility maximization by rational agents". 
Starting from this approach, the development of the "precautionary saving model of optimal foreign reserves" seems more appropriate: however it still fails to be suited to the China' case. Finally the authors propose to model the behavior of Chinese Central banker influenced by loss aversion and narrow framing, inserting the cognitive biases into the precautionary savings approach to holding reserves, facing uncertainty due to the recent global financial crisis.

Richard Herd in his paper The Evolution of China's Social Policies presents a very comprehensive overall picture of the critical social and socio-economic conditions that affect still many brackets of the population in China. The assessment of the policy conceptions, their legal basis, the degree of coverage of both, the pensions schemes and the health care provisions, as well their financial coverage, are analysed in depth. The growing income inequalities, the deepening of the ruralurban disparities, the dramatic insufficient health system coverage, the still fundamentally discriminated positions of migrant workers vis-à-vis public services, the lack of pension scheme for the elderly, reflect the severe insufficiencies of the present social safety-net and pension policies. Instead of important reduction of the poverty rate, these backwardness and insufficiencies are an handicap for an economy that is searching to up-grade its growth. The author analyses in great details the critical aspects still to be improved, considering the size of the territory and the local conditions' disparities across the country, as public services tend to concentrate around the urban areas, whilst rural areas suffer more the difficulties of access to them. The collection of data by the tool of surveys, for measuring the real degree of needs and the state of the policy achievements so far, remains very problematic. The methodological uncertainties concerning the measure of the phenomena therefore is also an obstacle to the policy-maker process. The conclusions underline the still low level of social insurance coverage, exacerbated by the fragmentation of the services as each city has own fund: this rends difficult to regulate the provision of service, in particular in the least developed areas, unable to collect enough local revenue for sustaining such costs. A more integrated national policy would be necessary in order to overcome such disparities in social security provision.

\section{References}

Fardoust S, Lin JY, Luo X (2012) Demystifying China's fiscal stimulus. Policy research working paper, no 6221, World Bank, p 35

International Monetary Fund (2011) People's Republic of China: financial system stability assessment. Washington, DC

International Monetary Fund (2012) People's Republic of China, country report, no 12/195, p 75

Lardy NR (2012) Sustaining China's economic growth after the global financial crisis. Peterson Institute for International Economics, Washington, DC

Lin JY (2004) Lessons of China's transition from a planned economy to a market economy. China Center for Economic Research, working paper 2004-2, p 40

Lin JY (2011) Demystifying the Chinese economy. Cambridge University Press, Cambridge

OECD (2010) Economic surveys: China, Paris 
Subramanian A (2011) Eclipse: living in the shadow of China's economic dominance. Peterson Institute of International Economics, Washington, DC, p 106

World Bank (2012) China 2030, building a modern, harmonious, and creative high-income, society. WB and Development Research Center of the State Council, the People's Republic of China, Washington, DC, p 468 